\title{
Application of Electrical Resistivity Imaging for Engineering Site Investigation. A Case Study on Prospective Hospital Site, Varamin, Iran
}

\author{
Amin AMINI and Hamidreza RAMAZI \\ Department of Mining and Metallurgical Engineering, \\ Amirkabir University of Technology, Tehran, Iran; \\ e-mail: ramazi@aut.ac.ir
}

\begin{abstract}
The article addresses the application of electrical resistivity imaging for engineering site investigation in Pishva Hospital, Varamin, Iran. Some aqueduct shafts exist in the study area backfilled by loose materials. The goals of this study are to detect probable aqueduct tunnels and their depth, investigate filling quality in the shafts as well as connection(s) between them. Therefore, three profiles were surveyed by dipoledipole electrode array. Also, to investigate the potentially anomalous areas more accurately, five additional resistivity profiles were measured by a Combined Resistivity Sounding-Profiling array (CRSP). According to the results of 2-D inversion modelling, a main aqueduct tunnel was detected beneath the central part of the site. Finally, the resistivity pattern of the detected aqueduct system passing the investigated area was provided using the obtained results.
\end{abstract}

Key words: electrical resistivity imaging, cavity detection, CRSP array, Qanat. 


\section{INTRODUCTION}

Civil engineering projects are usually dealing with geological and geotechnical problems. Conducting these projects in urban areas has several critical and special problems (Dindarloo and Siami-Irdemoosa 2015, Fang et al. 2016). Lack of scientific attention to them can cause noticeable damages or even disasters (e.g., BBC News 2015). Channels, underground cavities, wells, aqueducts and other obsolete man-made underground structures which may be buried now or in the near future are among the most crucial geotechnical and geological problems in urban areas (Fig. 1). The underground void spaces of this kind (empty or filled by loose materials) usually cause weak points in the ground and, therefore, there is an urgent need to identify, map and compile them. Various methods have been used to study the abovementioned phenomena. Geophysical methods are considered as the fastest and most affordable of them (Benson 1995, Burger 1992, Cosenza et al. 2006, Gautam et al. 2000).

Electrical resistivity method has been widely used due to low operation costs and its flexibility for many geological conditions (Van Schoor 2002, Zhou et al. 2002). The purpose of the resistivity method is to detect underground inhomogeneities and interpret them as modifications in underground materials or structures. Resistivity method is widely used in fields such as mineral exploration, environmental investigations, geotechnical studies, hydrology and hydrogeology (e.g., Asfahani and Abou Zakhem 2013, Bayrak

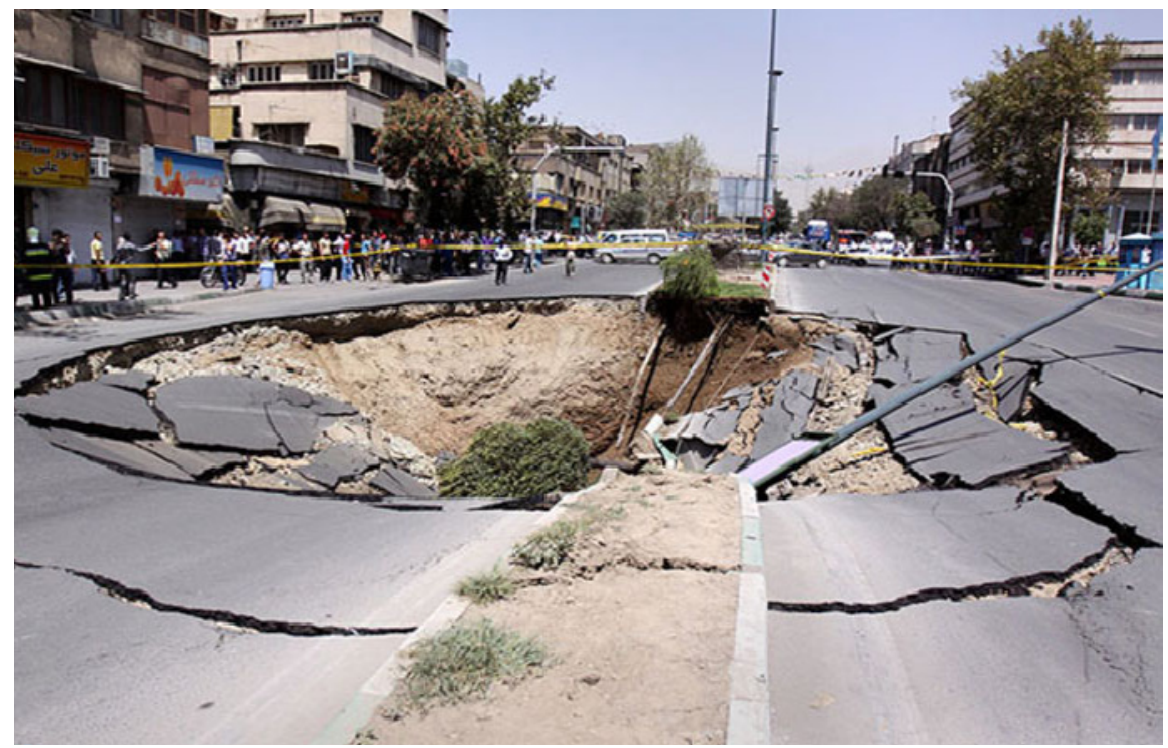

Fig. 1. Surface settlement of Navab Str., Tehran, Iran, due to an obsolete Qanat tunnel collapse (Donya-e eqtesad 2009). 
and Senel 2012, Candansayar and Başokur 2001, Fehdi et al. 2011, Giang et al. 2013, Hee et al. 2010, Loke and Barker 1996, Narayan et al. 1994, Papadopoulos et al. 2007, Wilkinson et al. 2010, Winters et al. 2015).

In Iran, systems of underground aqueducts called Qanats were constructed in past millenniums, including a series of well-like vertical shafts, connected by gently sloping tunnels. This technique taps into subterranean water in a manner that delivers water to the surface without the need for pumping (Fig. 2). Most of the old Qanats are obsolete nowadays, but their structures still exist (Semsar Yazdi and Askarzadeh 2007, ICQHS 2015).

In this paper a case study is discussed to demonstrate the application of the electrical resistivity method to investigate foundation of a prospective hospital site to detect probable weak zones and/ or cavities due to an abandoned Qanat system.
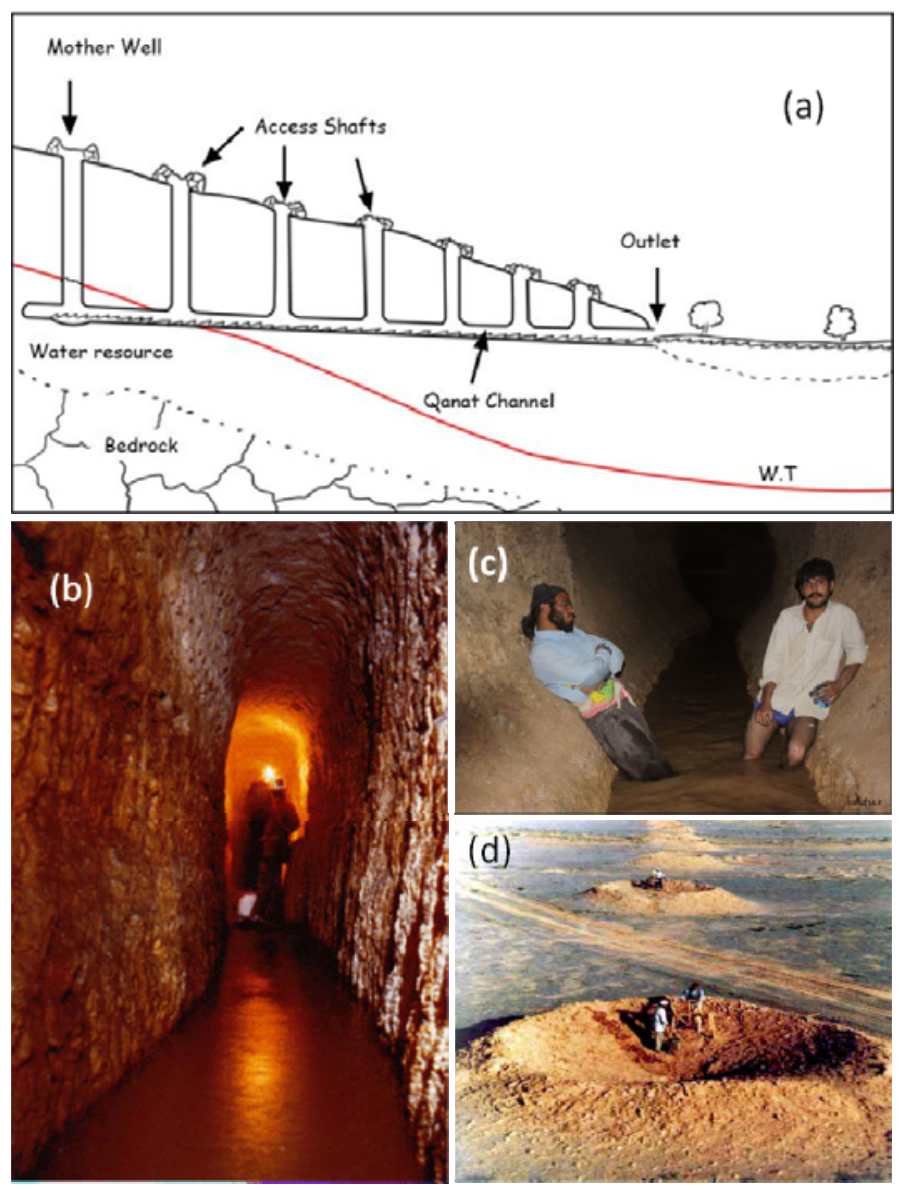

Fig. 2: (a) Schematic section showing the Qanat system; (b, c, and d) typical pictures showing Qanats features. 


\section{STUDY AREA}

The Pishva Hospital site is located in Pishva town, $70 \mathrm{~km}$ southeast of Tehran, the capital city of Iran (Fig. 3). Pishva town is located on a large plain which is dominantly covered by agricultural soils with thicknesses ranging from $1 \mathrm{~m}$ to more than $5 \mathrm{~m}$ laid on young fine grain alluviums. Previous geotechnical investigation at the area reported that the thickness of the alluvium layer changes from $8 \mathrm{~m}$ in the north to over $18 \mathrm{~m}$ in the southern part of the town. Although the second layer is partially formed of a few sub-layers with different thicknesses, they can be considered together as a single geoelectrical unit. The alluvium layer is laid on an impermeable silty layer. Pishva town has been constructed on old farmlands, so interestingly but not surprisingly lots of Qanat shafts still exist in the town, as expected. The main field information is the following: Previous investigations on Qanats show that ancient people dug the Qanats tunnels into the silt layer in this area, and several abandoned Qanat shafts traces could be observed at the Pishva Hospital site, suggesting that a Qanat system exists beneath the area. Most of the shafts were backfilled by people because of safety problems. Part of the study area has been levelled by municipality contractors (see Fig. 3). Based on local habitants' sayings there should be seven aqueduct shafts in the area.

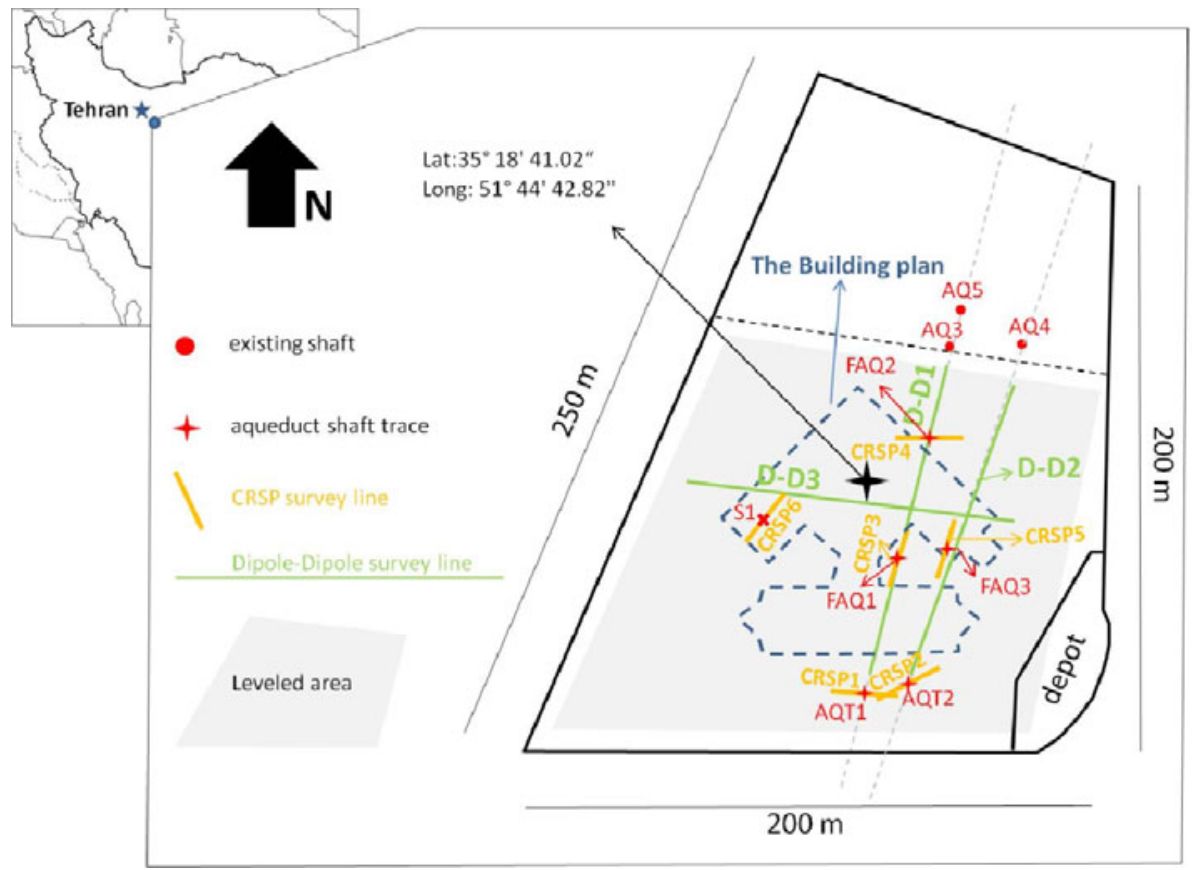

Fig. 3. Plan view of Pishva Hospital site. Locations of the survey lines are identified in the figure. 
The existing shafts are located along two more-or-less parallel lines with a north-south trend, so we supposed that two parallel Qanat tunnels connect $\mathrm{N}-\mathrm{S}$ trending contiguous shafts. For example, we assumed that shafts AQ5, AQ3, and AQT1 are connected together as well as shafts AQ4 and AQT2 through parallel tunnels.

\section{SURVEY DESIGNING AND DATA ACQUISITION}

In this study, we used a CRSP array (Ramazi 2005) to conduct detailed electrical resistivity imaging (ERI) surveys. The data obtained from this array could be applied not only for ERI but also for vertical electrical soundings (VES) interpretation. The main purpose of the application of this array is to compile ERI sections. By CRSP array, three VES are constructed simultaneously by a set of measurements. In this array the distance of measuring stations is equal to the spacing of the potential electrodes (Fig. 4). As shown in the figure, CRSP could be similar to the Schlumberger and WennerSchlumberger arrays in central measurements; however, potential electrode spacing could be decreased for shorter current electrode distances. The CRSP provides an enhanced lateral and in depth coverage, due to the acquisition of more data in a section (Fig. 4). The CRSP has been successfully applied to different mineral exploration and engineering site investigations (see Amini and Ramazi 2016, Ramazi and Jalali 2014, and Ramazi and Mostafaie 2013, for further details).

Designing of the survey lines was done in four steps as follows:

- Two CRSP profiles, with a maximum current length of $150 \mathrm{~m}$ and electrode spacing of $3 \mathrm{~m}$, were surveyed in the locations of AQT1 and AQT2, mainly to study the backfilled shafts and their filling quality.

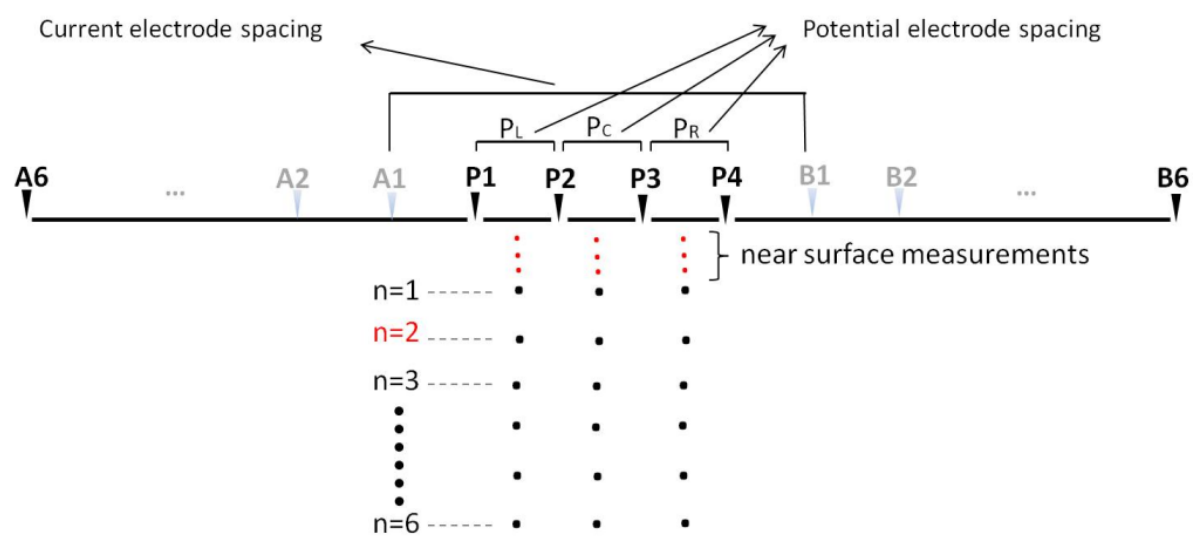

Fig. 4. Schematic section along CRSP electrode array. 
- Three dipole-dipole profiles were conducted to have data coverage of the study area. Two parallel conventional inline surface dipole-dipole profiles of $110 \mathrm{~m}$ in length, dipole spacing of $5 \mathrm{~m}$ and a maximum dipole length of $80 \mathrm{~m}(n=16)$ were conducted in a direction of north-south. Also, to detect other probable existing aqueduct tunnels, a dipole-dipole profile with a length of $110 \mathrm{~m}$ and dipole spacing of $5 \mathrm{~m}$ was designed in the west-east direction.

a Three CRSP profiles with a maximum current length of $150 \mathrm{~m}$ and electrode spacing of $3 \mathrm{~m}$ were conducted for obtaining more detailed data about the anomalies found in the previous step. The CRSP profiles were carried out on the anomalies locations (CRSP3, 4, and 5).

- A CRSP profile, with a maximum current length of $150 \mathrm{~m}$ and electrode spacing of $3 \mathrm{~m}$, was carried out in location of $\mathrm{S} 1$, to obtain a sequence of geological layers. Based on the observations, this location was expected to be fresh and geological layers should be normal.

The data acquisition was carried out by a WDJD-3 RS-IP measurement system using single channel mode. All measurements were repeated for three to five times to ensure data quality. The acquired apparent resistivity data were inverted by the RES2DINV (commercially available) software Ver. 3.54 and the results were drawn into $2 \mathrm{D}$ resistivity sections using the SURFER software Ver. 10. All profiles were surveyed in the flattened area, so no topographic correction was needed to be applied on the acquired data (Fig. 3). Inversion parameters were selected so that the best image of the subsurface would be achieved. Finite differences method was applied with finest grid option to carry out forward models; the method of inversion was set as combined inversion method (i.e., the combination of Marquardt and Occam inversion) and the starting model was set as the average of the measured apparent resistivity data).

\section{RESULTS AND DISCUSSION}

Figures 5 to 8 show the resistivity inverted images along surveyed profiles. From the inverted resistivity images, three resistivity layers were overall distinguished (in the all dipole-dipole and CRSP images and also in the VES curve obtained from CRSP6 measurements), which are more or less coincided with geological layers in the area: a surficial resistivity layer of 45$70 \mathrm{ohm}-\mathrm{m}$ consisting top soils and loose materials and having a thicknesses of 2-5 m; an intermediate resistivity layer of $15-40 \mathrm{ohm}-\mathrm{m}$ is inferred to be fine grained alluviums with an average thickness of 12-13 m; and a deeper third resistivity layer of $5-15 \mathrm{ohm}-\mathrm{m}$ that seems to relate to the basal silty layer (as the bedrock). Along the dipole-dipole profiles, three high resistivity anomalies were detected. The detected anomalies could be related to the 


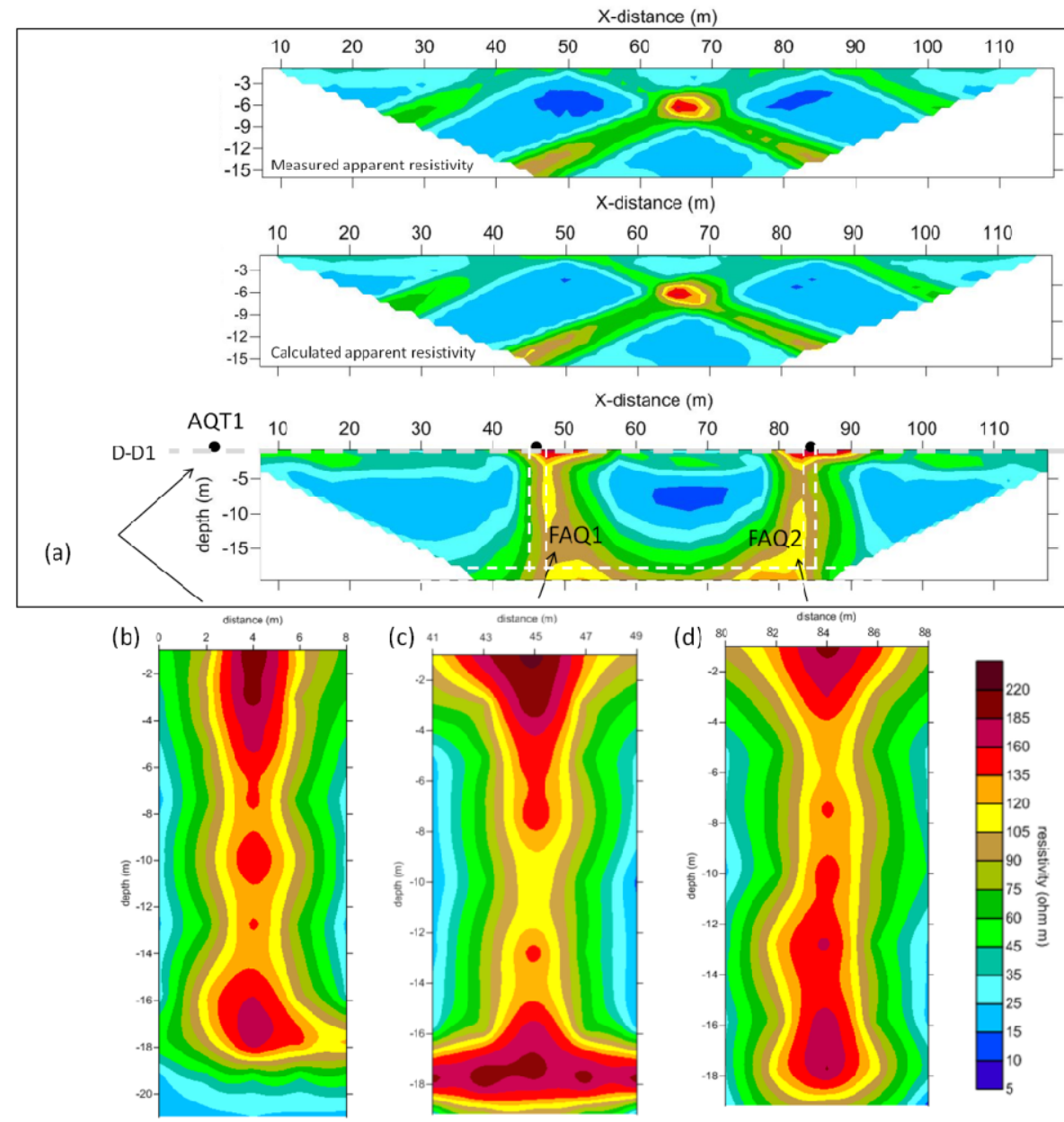

Fig. 5: (a) Inverted resistivity image along survey line D-D1. Pseudo-sections of measured and calculated apparent resistivity data (iteration 5) are also included in the figure. The RMS error was calculated as 0.07 ; (b) Inverted resistivity image along survey line CRSP1. This image shows the filling quality of the shaft AQ1; (c) Inverted resistivity image along survey line CRSP3; (d) Inverted resistivity section along the survey line CRSP4. The direction of the profile line is perpendicular to D-D1.

Qanat shafts. Figure 5a shows the inverted resistivity image along the survey line D-D1. Two high resistivity anomalies (FAQ1 and FAQ2) are observed in the image which seems to be due to hidden backfilled Qanat shafts. As seen in Fig. 5a, a tunnel passes along the survey line orientation. The depth of the tunnel is estimated at almost 17 to $18 \mathrm{~m}$. It could be inferred that at 
least Qanat shafts AQT1, AQ3, AQ5 and two other shafts found are connected through the detected tunnel. Figure $5 \mathrm{~b}$ shows the inverted resistivity image along survey line CRSP1. Because of constrains with southern fence of the site, we decided to conduct CRSP1 in a direction of west-east so that the probable tunnel connecting AQT1 to AQT2 could be detected. The AQ1 filling quality could be followed through CRSP1 inverted resistivity image. The length of the shaft is estimated to be a little more than $18 \mathrm{~m}$. Figure $5 \mathrm{c}$ illustrates the inverted resistivity image along the survey line CRSP 3 carried out on the location of FAQ1. The detected tunnel in profile D-D1 is also observed. A local partial tunnel collapse has made a considerable cavity at the intersection of the shaft and the tunnel. Figure $5 \mathrm{~d}$ shows the inverted resistivity image along the survey line CRSP4 which was conducted to obtain a more detailed image on found anomaly FAQ2. Through this section, shaft FAQ2 filling quality can be followed. The length of the shaft is estimated to be about $18 \mathrm{~m}$. The rounded section of the bottom of the shaft confirms that the connected tunnel to the FAQ2 is perpendicular to the survey line direction.

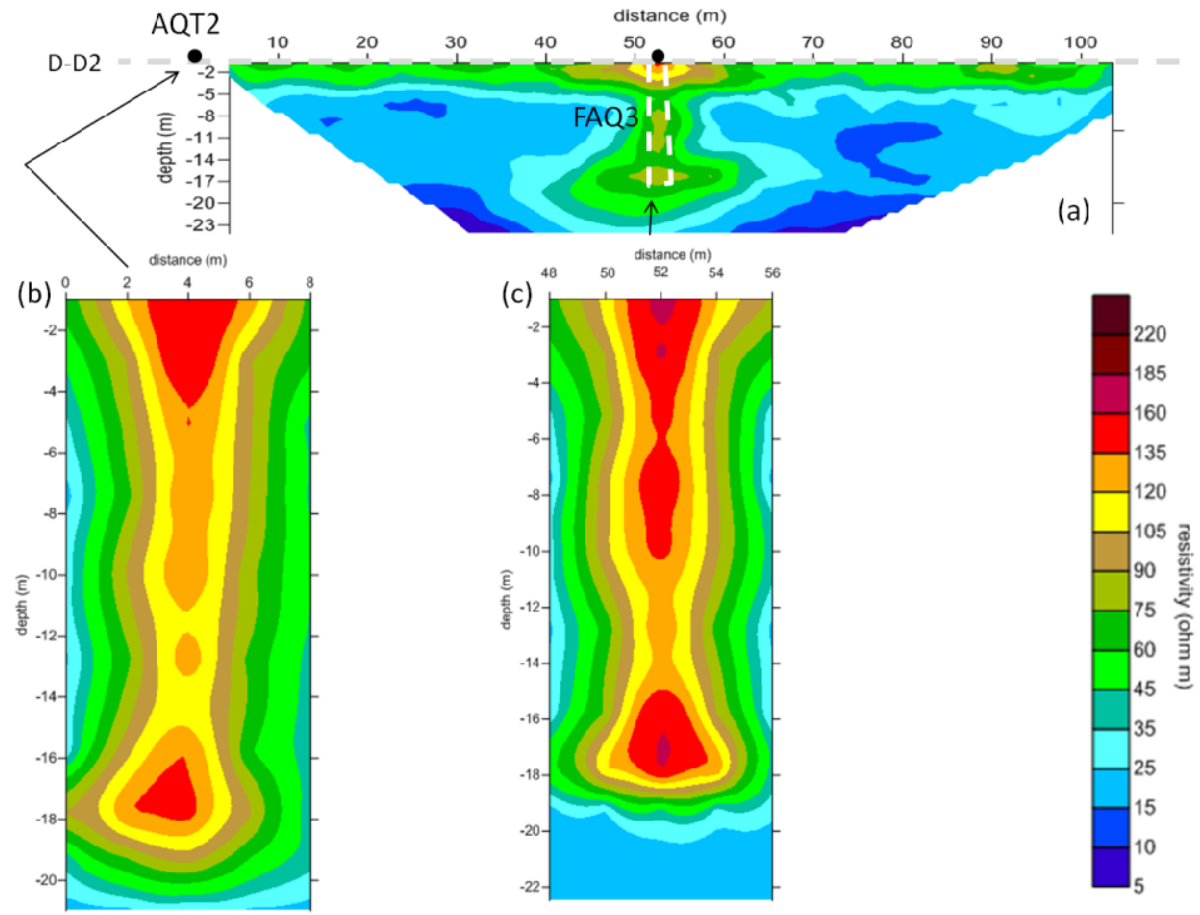

Fig. 6: (a) Inverted resistivity image along survey line D-D2. FAQ3 is distinguishable in the image; (b) Inverted resistivity image along survey line CRSP2. Filling quality of shaft AQT2 is seen in this section; (c) Inverted resistivity section along the survey line CRSP5. The direction of the profile line is parallel to D-D2. 
Figure 6a shows the inverted resistivity image along survey line D-D2. A relatively high resistivity anomaly (FAQ3) is visible in the section, suggesting a backfilled Qanat shaft's trace but no tunnel could be detectable along the survey line orientation. According to the shape of the anomaly it could be inferred that survey line D-D2 is not exactly over FAQ3 location (Fig. 3); therefore, the intensity of this anomaly is lower than the anomalies found in the survey line D-D1. The inverted resistivity image along survey line CRSP2 is shown by Fig. 6b. The direction of CRSP2 is such that the tunnel connecting the AQT2 to the AQT1 could be detected. The length of shaft AQ2 is estimated at about $18 \mathrm{~m}$. We conducted a CRSP survey to obtain a more detailed image on the detected anomaly by D-D2 profile (Fig. 6c). Through this section, the FAQ3 filling quality can be followed. The length of the shaft FAQ3 is estimated to be $18 \mathrm{~m}$. The shape of the shaft's bottom confirms the connected tunnel to shaft FAQ3 is perpendicular to the survey line CRSP5; considering the observation and detected shaft FAQ1 along survey line D-D1, FAQ3 seems to be connected to FAQ1.
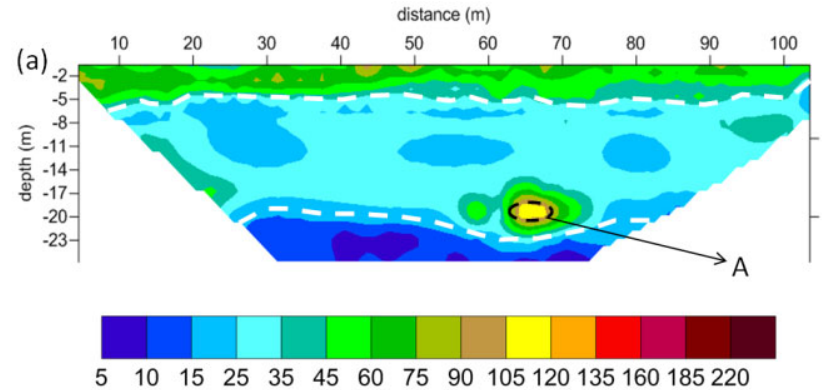

(c)

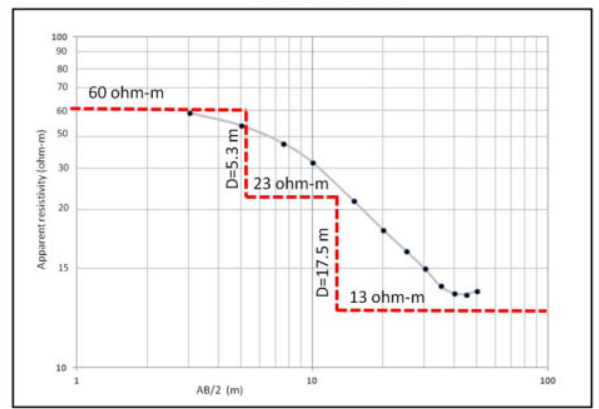

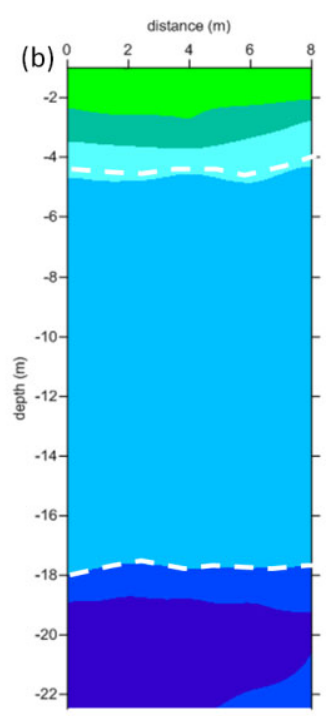

Fig. 7: (a) Inverted resistivity image along survey line D-D3. Three main resistivity layers are distinguishable in the image. The anomaly remarked with " $\mathrm{A}$ " belongs to a potential connection tunnel; (b) Inverted resistivity image along the survey line CRSP6. In conjunction with the inverted resistivity image along the survey line DD2, the main resistivity layers could be also distinguished; (c) 1-D resistivity inversion along CRSP5-c sounding curve. 

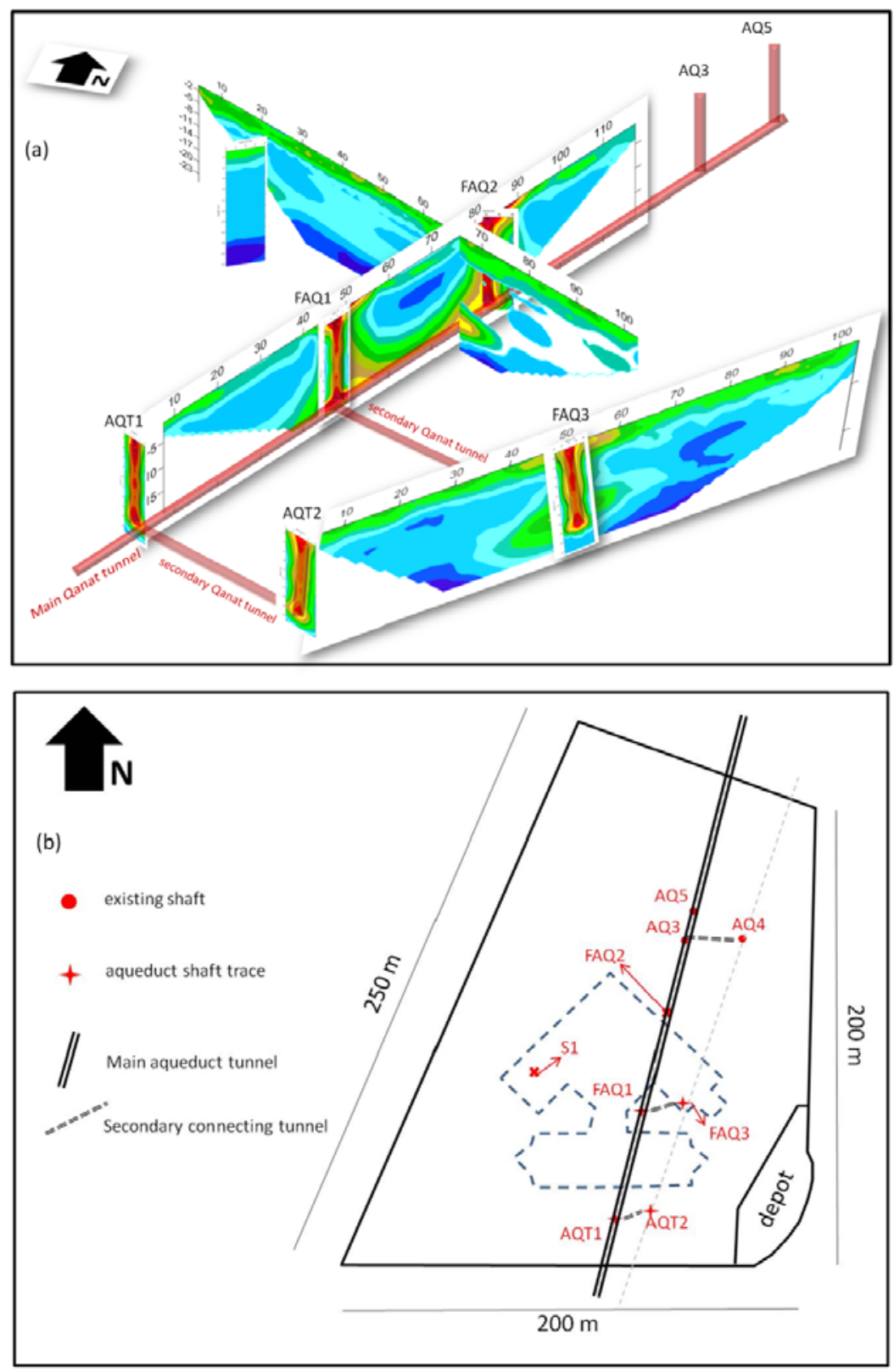

Fig. 8: (a) Quasi-3D schema of the aqueduct system derived from inverted resistivity images; (b) resulted plan of the aqueduct system paths. The main tunnel passes the shafts AQT1, FAQ1, FAQ2, AQ3, and AQ5. Shafts AQT2, FAQ3, and AQ4 are connected to shafts AQT1, FAQ1, and AQ3, respectively, through secondary tunnels. 
Figure 7a presents the inverted resistivity image along survey line D-D3. A high resistivity anomaly of $100-120 \mathrm{ohm}-\mathrm{m}$ is marked in the figure with letter "A", which seems to be the effect of a passing tunnel across the survey line. Considering the location of the detected anomaly, it should be the trace of detected tunnel in survey line D-D1. Survey line CRSP6 was conducted to explore a sequence of geological layers of the area. As expected, no important anomalies could be detected in this section. We also carried out 1-D inversion on sounding data along this profile (Fig. 7c). The results confirm three main resistivity layers in this section.

Finally, with regard to the information gained by resistivity imaging along the survey lines, the plan of the abandoned aqueduct paths was drawn. The main tunnel of the Qanat system is located in the central part of the hospital site and its orientation is almost north-south. The shafts located in the eastern side of the area are connected to the main tunnel through secondary tunnels with almost west-east orientation (Fig. 8).

\section{CONCLUSION}

The main goal of this article was investigating probable weak zones and/or cavities, at the of Pishva Hospital site, by using 2D electrical resistivity imaging. Our results indicate that the conducted method could detect the objectives with an acceptable precision. Three main resistivity layers were distinguished in the resistivity images D-D3 (as well as in inversion image CRSP6), which are in agreement with the local stratigraphy. The results arisen from the dipole-dipole profiles provided a satisfying coverage of the investigation area so that the main Qanat tunnel was detected as a resistivity anomaly in the resistivity section D-D1, as well as the aqueduct shafts traces FAQ1 and FAQ2. The effect of shaft FAQ3 was also detected through D-D2 profile. In conjunction with the dipole-dipole inverted resistivity images, the CRSP could provide detailed information of the aqueduct shafts so that cavities and/or weak points along the shafts fillings could be observed in the resulting inverted resistivity images, due to their anomalous resistivity signature.

\section{References}

Amini, A., and H.R. Ramazi (2016), Anomaly enhancement in 2-D Electrical resistivity imaging method using residual resistivity technique, J. Southern Afr. Inst. Min. Metall. 116, 2, 161-168, DOI: 10.17159/2411-9717/2016/ v116n2a7. 
Asfahani, J., and B. Abou Zakhem (2013), Geoelectrical and hydrochemical investigations for characterizing the salt water intrusion in the Khanasser valley, northern Syria, Acta Geophys. 61, 2, 422-444, DOI: 10.2478/s11600-0120071-3.

Bayrak, M., and L. Senel (2012), Two-dimensional resistivity imaging in the Kestelek boron area by VLF and DC resistivity methods, J. Appl. Geophys. 82, 1-10, DOI: 10.1016/0926-9851(95)90040-3.

BBC News (2015), Grays sinkhole caused by quarry tunnel collapse, say experts, BBC News, available from: http://www.bbc.com/news/uk-england-essex32921411(accessed: 11 November 2015).

Benson, A.K. (1995), Applications of ground penetrating radar in assessing some geological hazards: examples of groundwater contamination, faults, cavities, J. Appl. Geophys. 33, 1-3, 177-193, DOI: 10.1016/0926-9851(95) 90040-3.

Burger, H.R. (1992), Exploration Geophysics of the Shallow Subsurface, PrenticeHall, Englewood Cliffs, 489 pp.

Candansayar, M.E., and A.T. Basokur (2001), Detecting small scale targets by the 2D inversion of two-sided three- electrode data: application to an archaeological survey, Geophys. Prospect. 49, 1, 13-25, DOI: 10.1046/j.13652478.2001.00233.x.

Cosenza, P., E. Marmet, F. Rejiba, Y.J. Cui, A. Tabbagh, and Y.Charlery (2006), Correlations between geotechnical and electrical data: A case study at Garchy in France, J. Appl. Geophys. 60, 3-4, 165-178, DOI: 10.1016/j.jappgeo. 2006.02.003.

Dindarloo, S., and E. Siami-Irdemoosa (2015), Maximum surface settlement based classification of shallow tunnels in soft ground, Tunn. Undergr. Sp. Tech. 49, 320-327, 320-327, DOI: 10.1016/j.tust.2015.04.021.

Donya-e eqtesad (2009), Obsolete Qanats caused Tohid tunnel collapse, Donya-e eqtesad newspaper, available from: http:/www.donya-e-eqtesad.com/news/ 568474 (accessed: 10 November 2015).

Fang, Q., Q. Tai, D. Zhang, and L. Wong (2016), Ground surface settlements due to construction of closely-spaced twin tunnels with different geometric arrangements, Tunn. Undergr. Sp. Tech. 51, 144-151, DOI: 10.1016/j.tust. 2015.10.031, 144-151.

Fehdi, C., F. Baali, D. Boubaya, and A. Rouabhia (2011), Detection of sinkholes using $2 \mathrm{D}$ electrical resistivity imaging in the Cheria Basin (north-east of Algeria), Arab. J. Geosci. 14, 1-2, 181-187, DOI: 10.1007/s12517-009-01172.

Gautam, P., R.P. Surendra, and A. Hisao (2000), Mapping of subsurface karst structure with gamma ray and electrical resistivity profiles: a case study from Pokhara valley, central Nepal, J. Appl. Geophys. 45, 2, 97-110, DOI: 10.1016/S0926-9851(00)00022-7. 
Giang, N.V., N.B. Duan, L. Thanh, and N. Hida (2013), Geophysical techniques to aquifer locating and monitoring for industrial zones in North Hanoi, Vietnam, Acta Geophys. 61, 6, 1573-1597, DOI: 10.2478/s11600-013-0147-8.

Hee, S.H., S.K. Dae, and J.P. Inn (2010), Application of electrical resistivity techniques to detect weakened fracture zones during underground construction, Environ. Earth Sci. 60, 4, 723-731, DOI: 10.1007/s12665-009-0210-6.

ICQHS (2015), ICQHS official website available from: http://icqhs.org/ SC.php? type $=$ staticandid $=25$ (accessed: 11 November 2015 ).

Loke, M., and R. Barker (1996), Rapid least squares inversion of apparent resistivity pseudosections using a quasi Newton's method, Geophys. Prospect. 44, 1, 131-152, DOI: 10.1111/j.1365-2478.1996.tb00142.x.

Narayan, S., M.B. Dusseault, and D.C. Nobes (1994), Inversion techniques applied to resistivity inverse problems, Inverse Probl. 10, 3, 669-686, DOI: 10.1088/0266-5611/10/3/011.

Papadopoulos, N.G., P. Tsourlos, G.N. Tsokas, and A. Sarris (2007), Efficient ERT measuring and inversion strategies for 3D imaging of buried antiquities, Near Surf. Geophys. 5, 6, 349-361, DOI: 10.3997/1873-0604.2007017.

Ramazi, H.R. (2005), Combined resistivity sounding and profiling and its application in mineral exploration and site investigation, Technical Report, Tehran, 21 pp. (in Persian).

Ramazi, H.R., and M. Jalali (2014), Contribution of geophysical inversion theory and geostatistical simulation to determine geoelectrical anomalies, Stud. Geophys. Geod. 59, 1, 97-112, DOI: 10.1007/s11200-013-0772-3.

Ramazi, H.R., and K. Mostafaie (2013), Application of integrated geoelectrical methods in Marand (Iran) manganese deposit exploration, Arab. J. Geosci. 6, 8, 2961-2970, DOI: 10.1007/s12517-012-0537-2.

Semsar Yazdi, A., and S. Askarzadeh (2007), A historical review on the Qanats and historic hydraulic structures of Iran since the first millennium B.C., International History Seminar on Irrigation and Drainage, Tehran, Iran.

Van Schoor, M. (2002), Detection of sinkholes using 2D electrical resistivity imaging, J. Appl. Geophys. 50, 4, 393-399, DOI: 10.1016/S0926-9851(02) 00166-0.

Wilkinson, P.B., P.I. Meldrumm, O. Kuras, J.E. Chambers, S.J. Holyoake, and R.D. Ogilvy (2010), High-resolution electrical resistivity tomography monitoring of a tracer test in a confined aquifer, J. Appl. Geophys. 70, 4, 268-276, DOI: 10.1016/j.jappgeo.2009.08.001.

Winters, G., I. Ryvkin, T. Rudkov, Z. Moreno, and A. Furman (2015), Mapping underground layers in the super arid Gidron Wadi using electrical resistivity tomography (ERT), J. Arid Environ. 121, 79-83, DOI: 10.1016/j.jaridenv. 2015.05.008. 
Zhou, W., B.F. Beck, and A.L. Adams (2002), Effective electrode array in mapping karst hazards in electrical resistivity tomography, Environ. Geol. 42, 8, 922928, DOI: 10.1007/s00254-002-0594-zv.

Received 7 September 2015

Received in revised form 26 January 2016

Accepted 3 February 2016 